\title{
Asymptomatic Coarctation of the Aorta in a Middle-Aged Man: The Significance of Physical Examination
}

Sidra Javed MBBS and Hamid Reza Habibi

DOI: $10.22374 /$ cjgim.v13i1.217

\section{About the Authors}

Sidra Javed is a 3rd year internal medicine resident in the Department of Medicine, University of Calgary, Cumming School of Medicine, Calgary, Alberta, Canada.

Hamid Reza Habibi is a clinical associate professor in the Department of Cardiac Sciences, University of Calgary, Alberta, Canada. Correspondence may be directed to: sidra.javed@albertahealthservices.ca

Submitted: June 11, 2017; Accepted: November 13, 2017. Published: March 5, 2018.

\begin{abstract}
Coarctation of the aorta is narrowing of the aorta that impedes normal blood flow. This condition is associated with a high mortality rate if untreated. It rarely presents in adulthood, especially in Canada, due to early childhood screening. We report a case of a middle-aged newly immigrated gentleman with a history of hypertension who was incidentally found to have some physical examination findings concerning for coarctation of the aorta. Subsequent imaging studies not only confirmed this diagnosis but also found other cardiac complications commonly associated with it. Recently, he underwent surgical intervention, significantly impacting his mortality and morbidity. Our aim through this case report is to emphasize the importance of physical examination findings to detect such cases in unscreened immigrant populations.
\end{abstract}

\section{Résumé}

La coarctation de l'aorte consiste en un rétrécissement de l'aorte qui empêche la circulation normale du sang. Si non traitée, cette affection est associée à un taux de mortalité élevé. On l'observe rarement à lâge adulte, particulièrement au Canada, en raison d'un dépistage précoce dans l'enfance. Nous décrivons le cas d'un homme d'âge moyen, nouvellement immigré, avec des antécédents d'hypertension, chez lequel certaines observations à l'examen physique indiquaient la présence d'une coarctation de l'aorte. Des examens d'imagerie subséquents ont non seulement confirmé ce diagnostic, mais ont également révélé d’autres complications cardiaques couramment associées. L'homme a récemment subi une intervention chirurgicale, qui a influé significativement sur ses risques de mortalité et de morbidité. Par cet exposé de cas, nous souhaitons souligner l'importance des observations relevées à l'examen physique pour détecter de tels cas chez la population immigrante n’ayant pas subi de dépistage au préalable.

Coarctation of the Aorta (CoA) refers to the narrowing of the aorta usually in the region of ligamentum arteriosum that leads to blood flow obstruction. It accounts $4-6 \%$ of all congenital heart defects. ${ }^{1}$ It is related to other cardiac as well as extracardiac conditions. It rarely presents in adulthood because of early detection in childhood, especially in developed countries.
It is associated with high morbidity and mortality. Average survival without treatment is 31 years. ${ }^{2}$ Physical examination is of paramount importance to detect these cases early.

We report an incidentally found asymptomatic aortic coarctation case in a male, 40-year-old Syrian immigrant who moved to Canada in early 2016. A "cardiac murmur" 
was picked up by a general practitioner on a routine complete physical examination. He was referred to cardiology service for further work up. His past medical history was significant only for hypertension (HTN) diagnosed in 2015 in Jordan where he moved prior to coming to Canada. He was started on ramipril $5 \mathrm{mg}$ daily. He had 20-pack-year smoking history. There was no family history of any cardiac abnormality noted. On examination, he was a thin man with a body mass index of $19.84 \mathrm{~kg} / \mathrm{m}^{2}$. Blood pressure in the right and left arm was 160/85 and 155/85, respectively, and right leg was $80 / 50$. No signs of heart failure were noted. Precordial examination revealed $2 / 6$ crescendo/ decrescendo mid peaking systolic murmur at the left sternal border with no radiation. A 2/6 diastolic murmur was present at 3 rd intercostal space at the left sternal border. A systolic flow murmur was noted at the back between thoracic spine and left scapular border. Bilateral femoral and pedal pulses were quite faint on palpation but present on Doppler study.

His examination was suspicious for aortic coarctation and aortic valve regurgitation which subsequently got confirmed on transthoracic echocardiogram (TTE). TTE also showed a bicuspid aortic valve with moderate to severe aortic regurgitation; and mild to moderately reduced left ventricular systolic function. He also had cardiac catheterization showing normal coronaries, but systolic pressure gradient of $100 \mathrm{mmHg}$ pre and post-coarctation (Figure 1 and Figure 2). To our surprise, abdominal imaging revealed an incidental finding of a horseshoe kidney.
American Heart Association (AHA) 2008 guidelines recommend treatment if peak to peak gradient is $>20 \mathrm{mmHg}$ or lesser with significant anatomical narrowing and evidence of collateral vessels. He recently had endovascular stent insertion based on these recommendations.

\section{Discussion}

CoA is rare to find in adults especially in Canada due to early childhood screening. Most adults present with uncontrolled hypertension. Patients may have other cardiac anomalies mainly hypoplastic left heart syndrome, atrioventricular (AV) canal defect, ventricular septal defect, and most commonly bicuspid aortic valve (50-75\%). ${ }^{3,6}$ A bicuspid aortic valve may or may not be complicated with aortic regurgitation, aortic stenosis, and dilated ascending aorta. Causes of death include heart failure, aortic rupture, bacterial endocarditis and intracranial hemorrhage. ${ }^{4,5} 25 \%$ of the cases will have extra-cardiac nonvascular manifestations including head and neck, musculoskeletal, gastrointestinal, genitourinary, and respiratory. CoA occurs in $35 \%$ of the patients with Turner syndrome. ${ }^{3,4}$

The presence of late systolic murmur anteriorly, as well as posteriorly, indicates collateral vessels which may make the gradient across the obstruction less severe than expected for the degree of obstruction. The presence of diastolic murmur points towards aortic regurgitation due to bicuspid aortic valve. The classic findings of aortic coarctation are systolic HTN in the upper extremities, brachio-femoral pulses delay, and low arterial blood

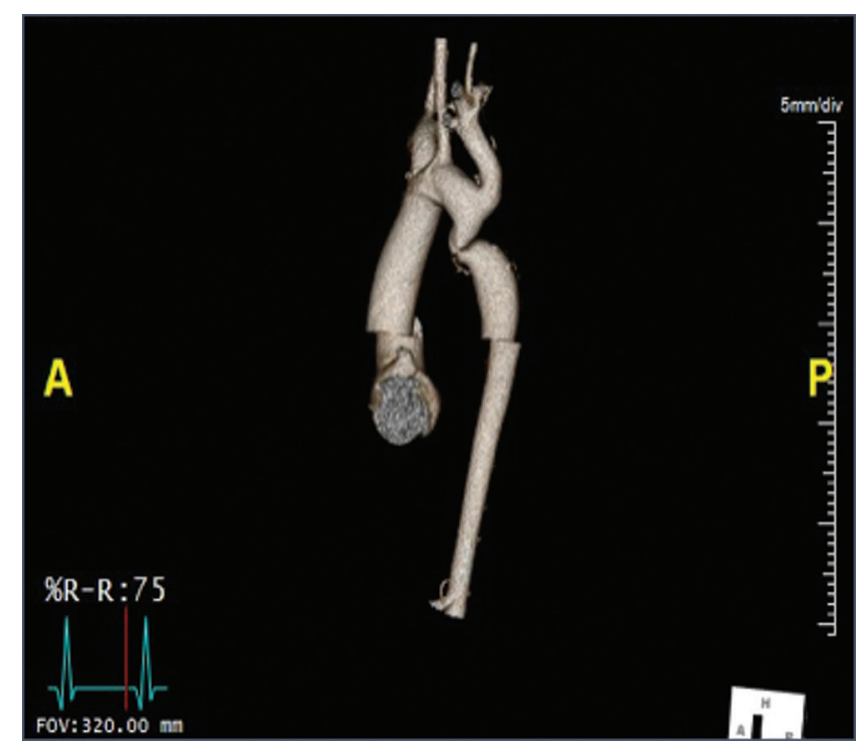

Figure 1. Left - Chest radiograph showing notched ribs due to dilated collateral vessels. Right - Computed tomography coronary enhanced showing severe aortic coarctation. 

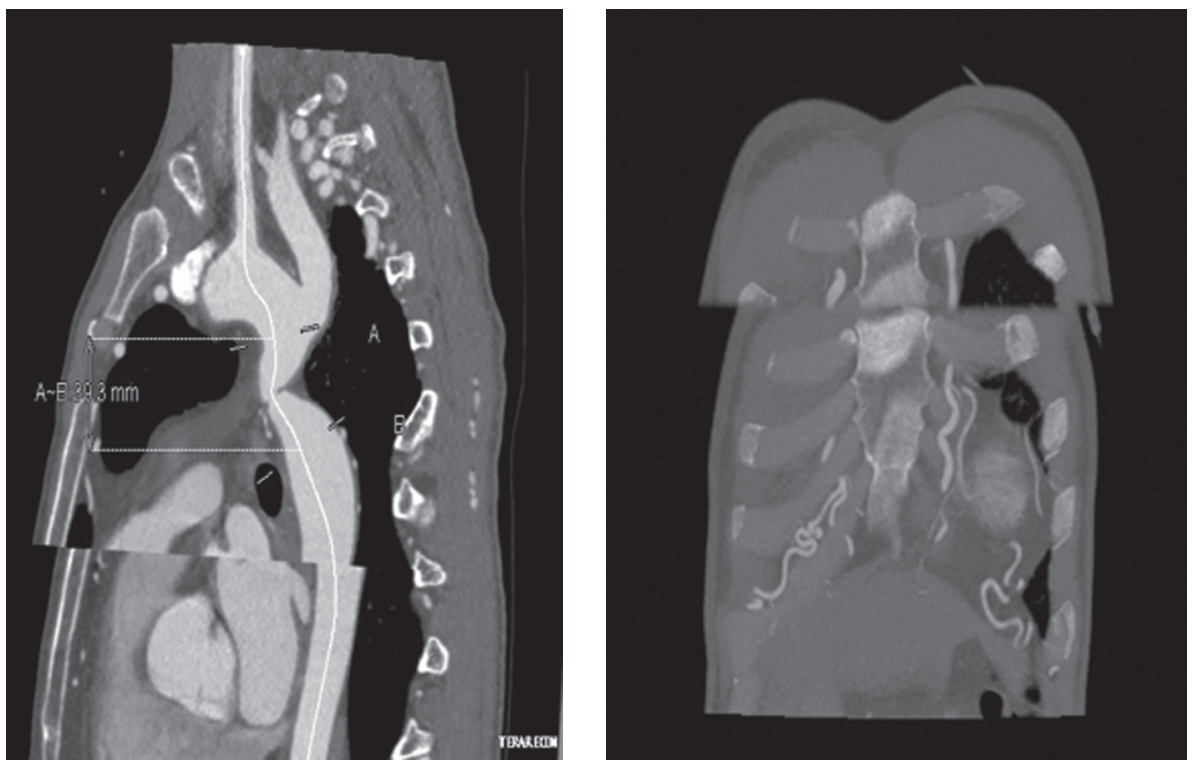

Figure 2 Right - Computed Tomography Angiogram (CTA) sagittal view demonstrating severe coarctation. Left - CTA coronal section showing thick collaterals.

pressure in the lower extremities. On precordial examination, along with normal heart sounds, a systolic ejection click and a systolic ejection murmur can be heard at the left sternal border representing bicuspid aortic valve. Large collateral vessels create systolic flow.

The clinical findings of differential pulses and blood pressure readings can be easily missed on routine physical examination if patients are not aware of having an underlying congenital disease. As imaging modalities are considered a primary screening tool, the Journal of American Medical Association(JAMA); rational clinical examination series does not evaluate the role of physical examination as it pertained to specific diagnostic questions for CoA.
Despite excellent survival rate post repair, the risk of morbidity is still high. Annual BP evaluation in all four limbs and conventional imaging of heart and aorta is warranted. Follow-up also includes 24 hours of BP measurement and exercise testing, as exercise-induced HTN can develop after repair which can lead to future systemic HTN. ${ }^{6,7}$ The AHA/ACC 2008 Recommendations for Clinical Evaluation and Follow Up are outlined below in Table 1 .

\section{Conclusion}

Not all cases are picked up in early childhood especially in unscreened immigrant populations. Detailed physical examination of hypertensive patients from these communities can help in

Table 1. AHA/ACC 2008 Recommendations for Clinical Evaluation and Follow Up ${ }^{4}$

\section{Class I}

- Every patient with systemic arterial hypertension should have the brachial and femoral pulses palpated simultaneously to assess timing and amplitude evaluation to search for the "brachial-femoral delay" of significant aortic coarctation. Supine bilateral arm (brachial artery) blood pressures and prone right or left supine leg (popliteal artery) blood pressures should be measured to search for differential pressure. (Level of Evidence: C)

- 2. Initial imaging and hemodynamic evaluation by TTE, including suprasternal notch acoustic windows, is useful in suspected aortic coarctation. (Level of Evidence: B)

- Every patient with coarctation (repaired or not) should have at least 1 cardiovascular magnetic resonance imaging or computed tomography scan for complete evaluation of the thoracic aorta and intracranial vessels. (Level of Evidence: B) 
early detection. The subsequent early intervention significantly impacts on the mortality and morbidity of these individuals.

\section{References}

1. Reller MD, Strickland MJ, Riehle-Colarusso T, et al. Prevalence of congenital heart defects in metropolitan Atlanta, 1998-2005. J Pediatr 2008;153:807.

2. Campbell M. Natural history of coarctation of aorta; Br Heart J 1970;32(5):633-40.

3. Baumgartner $\mathrm{H}$, Bonhoeffer P, De Groot NM, et al. ESC Guidelines for the management of grown-up congenital heart disease. Eur Heart J 2010 Dec;31(23):2915-57.
4. Warnes CA, Williams RG, Bashore TM, et al. ACC/AHA 2008 guidelines for the management of adults with congenital heart disease: Circulation 2008;118(23):e714.

5. Jenkins NP, Ward C. Coarctation of the aorta: natural history and outcome after surgical treatment. QJM 1999;92(7):365.

6. Bocelli A, Favilli S, Pollini I, et al. Prevalence and long-term predictors of left ventricular hypertrophy, late HTN, and hypertensive response to exercise after successful aortic coarctation repair. Pediatr Cardiol 2013;34:620-9.

7. Dijkema EJ, Leiner T, Grotenhuis HB. Diagnosis, imaging and clinical management of aortic coarctation. Br Heart J 2017 Aug;103(15):1148-1155. doi: 10.1136/heartjnl-2017-311173. 